\title{
Dose-response slope of forced oscillation and forced expiratory parameters in bronchial challenge testing
}

\author{
A.B. Bohadana*, R. Peslin**, S-E. Megherbi*, D. Teculescu*, E.A. Sauleau*, P. Wild*, Q.T. Pham*
}

Dose-response slope of forced oscillation and forced expiratory parameters in bronchial challenge testing. A.B. Bohadana, R. Peslin, S-E. Megherbi, D. Teculescu, E.A. Sauleau, P. Wild, Q.T. Pham. C) ERS Journals Ltd 1999.

ABSTRACT: In population studies, the provocative dose (PD) of bronchoconstrictor causing a significant decrement in lung function cannot be calculated for most subjects. Dose-response curves for carbachol were examined to determine whether this relationship can be summarized by means of a continuous index likely to be calculable for all subjects, namely the two-point dose response slope (DRS) of mean resistance $(R \mathrm{~m})$ and resistance at $10 \mathrm{~Hz}(R 10)$ measured by the forced oscillation technique (FOT).

Five doses of carbachol $(320 \mu \mathrm{g}$ each) were inhaled by 71 patients referred for investigation of asthma $(n=16)$, chronic cough $(n=15)$, nasal polyposis $(n=8)$, chronic rhinitis $(n=8)$, dyspnoea $(n=8)$, urticaria $(n=5)$, post-anaphylactic shock $(n=4)$ and miscellaneous conditions $(n=7)$. FOT resistance and forced expiratory volume in one second (FEV1) were measured in close succession. The PD of carbachol leading to a fall in FEV $1 \geq 20 \%$ (PD20) or a rise in $R \mathrm{~m}$ or $R 10 \geq 47 \%$ (PD47, $R \mathrm{~m}$ and PD47,R10) were calculated by interpolation. DRS for FEV1 (DRSFEV1), $R \mathrm{~m}(\mathrm{DRS} R \mathrm{~m})$ and $R 10(\mathrm{DRS} R \mathbf{1 0})$ were obtained as the percentage change at last dose divided by the total dose of carbachol. The sensitivity (Se) and specificity (Sp) of DRSRm, DRS10 $\Delta \% R \mathrm{~m}$ and $\triangle \% R 10$ in detecting spirometric bronchial hyperresponsiveness (BHR, fall in FEV1 $\geq \mathbf{2 0} \%$ ) were assessed by receiver operating characteristic (ROC) curves.

There were $23(32 \%)$ "spirometric" reactors. PD20 correlated strongly with DRSFEV 1 ( $\mathrm{r}=-0.962 ; \mathrm{p}=0.0001) ; \mathrm{PD} 47, \mathrm{R}_{\mathrm{m}}$ correlated significantly with $\mathrm{DRS} R \mathrm{~m}(\mathrm{r}=$ $-0.648 ; p=0.0001)$ and PD47, R10 with DRSR10 $(r=-0.552 ; p=0.0001)$. DRSFEV1 correlated significantly with both $D R S R m(r=0.700 ; p=0.0001)$ and $D R S R 10(r=0.784 ; p=0.0001)$. The Se and $S p$ of the various FOT indices to correctly detect spirometric BHR were as follows: DRSRm: $\mathrm{Se}=91.3 \%, \mathrm{Sp}=81.2 \%$; DRSR10: $\mathrm{Se}=91.3 \%, \mathrm{Sp}=95.8 \% ; \Delta \% R \mathrm{~m}: \mathrm{Se}=$ $86.9 \%, \mathrm{Sp}=52.1 \%$; and $\Delta \% R 10: \mathrm{Se}=91.3 \%, \mathrm{Sp}=58.3 \%$.

Dose-response slopes of indices of forced oscillation technique resistance, especially the dose-response slope of resistance at $10 \mathrm{~Hz}$ are proposed as simple quantitative indices of bronchial responsiveness which can be calculated for all subjects and that may be useful in occupational epidemiology.

Eur Respir J 1999; 13: 295-300.
*Institut National de la Santé et de la Recherche Médicale, INSERM, Unité 420, Epidémiologie Santé Travail; **Institut National de la Santé et de la Recherche Médicale, INSERM, Unité 14, Physiopathologie Respiratoire; "Institut National de Recherche et de Sécurité, INRS, Vandoeuvre-lès-Nancy, France

Correspondence: A.B. Bohadana INSERM Unité 420

Epidémiologie Santé Travail

BP 184- Avenue de la Forêt de Haye 54505 Vandoeuvre-lès-Nancy, Cedex France

Fax: 330383592596

Keywords: Bronchial responsiveness dose-response slope forced oscillation technique spirometry

Received: January 141997

Accepted after revision August 141998
Bronchial challenge tests with nonspecific stimuli are extensively used to assess bronchial responsiveness in the chest clinic [1] as well as in population [2] and occupational samples [3]. Usually, changes in airway calibre are evaluated by means of a pulmonary function test, the most widely used of which is the forced expiratory volume in one second (FEV1). However, FEV1 has two disadvantages: firstly, it requires full subject co-operation and, secondly, the deep respiratory manoeuvres required can cause changes in airway smooth muscle tone likely to influence the result of the test [4]. Airway resistance (Raw) measured by body plethysmography is sensitive and does not require forced expiratory manoeuvres but the equipment is cumbersome, expensive, and relatively complex to operate. Finally, impedance of the respiratory system measured by the forced oscillation technique (FOT) has several advantages over the above techniques: it requires only minimal subject co-operation, can be carried out during spontaneous breathing and, apparently, has no influence on bronchial contractility [5]. Furthermore, the equipment is cheaper and easier to operate than the body plethysmograph and, because of microcomputers, signal analysis takes only a few seconds, thus yielding results very quickly.

Clinical methodology for bronchial challenge testing has been standardized: the result is usually expressed as the provocative dose (PD) of bronchoconstrictor which causes a predetermined decrement in lung function (e.g. provocative dose causing $\geq 20 \%$ fall in FEV1 (PD20)) [6]. Although it has proven useful in the hospital laboratory, the PD approach is not appropriate for use in epidemiology. Indeed, in population samples most subjects do not experience the preset change in lung function even after inhalation of the last dose of bronchoconstrictor, being therefore excluded from the analysis. To overcome this limitation continuous response measures have been proposed which are based upon the calculation of the slope of 
the dose-response relationship by the fitting of different mathematical models to the data points [7-11]. By its simplicity the two-point linear dose-response slope (DRS) proposed by $\mathrm{O}^{\prime} \mathrm{CONNOR}$ et al. [11] has gained wide acceptance but, to the best of the authors knowledge, has been used to express spirometric (FEV1) data only.

The aim of the present study was, therefore, to investigate the validity of the two-point DRS of respiratory impedance measured by FOT as a quantitative index of bronchial responsiveness. FOT was performed first with spirometric measurements in close succession in patients undergoing routine bronchial challenge testing. Receiver operating characteristic (ROC) curves were then constructed to determine the sensitivity and specificity of DRS of FOT impedance in detecting bronchial hyperresponsiveness (BHR) defined spirometrically.

\section{Methods}

\section{Patients}

Seventy-one patients were evaluated at the pulmonary function laboratory of the Centre Hospitalier Universitaire de Nancy-Brabois, France. They were consecutive referrals for bronchial challenge testing as part of an investigation of asthma $(n=16)$, unexplained, persistent cough $(n=15)$, nasal polyposis $(n=8)$, chronic rhinitis $(n=8)$, dyspnoea $(n=8)$, urticaria $(n=5)$, post-anaphylactic shock $(n=4)$ and other miscellaneous conditions $(n=7)$. They were asked to stop theophylline and anticholinergics for $48 \mathrm{~h}$ and $\beta_{2}$ agonists for $12 \mathrm{~h}$ before the study. No patient was receiving regular treatment with inhaled steroids or disodium cromoglycate at the time of the study. The baseline characteristics of the study group are shown in table 1.

\section{Pulmonary function tests}

Total respiratory impedance $(\mathrm{Zrs})$ was measured using the forced oscillation system developed in the authors laboratory (Pulmosfor, SEFAM, Vandoeuvre, France), which has previously been described in detail [12]. Briefly, pseudorandom pressure variations from 4-32 Hz generated by a loudspeaker (90 W, Audax HD30 P45; HBN, Nancy,

Table 1. - Mean \pm sD anthropometriccharacteristics, smoking habits and baseline pulmonary function tests of patients $(n=71)$ undergoing routine carbachol bronchial challenge test

\begin{tabular}{lcc}
\hline Parameter & Observed & Per cent predicted \\
\hline Male/Female & $45 / 26$ & - \\
Age yrs & $39 \pm 14$ & - \\
Height cm & $167.1 \pm 7.8$ & - \\
Weight kg & $69.9 \pm 14.1$ & - \\
Nonsmokers & 30 & - \\
Smokers & $24(12.5 \pm 14.1$ pack-yrs $)$ & - \\
Exsmokers & $17(16.4 \pm 16.7$ pack-yrs $)$ & - \\
FEV1 L & $3.10 \pm 0.70$ & $96.8 \pm 13.4$ \\
FVC L & $3.66 \pm 0.79$ & $97.3 \pm 15.1$ \\
$V^{\prime}$ max, $50 ~ L \cdot s^{-1}$ & $3.94 \pm 1.22$ & $87.1 \pm 24.2$ \\
\hline
\end{tabular}

FEV1: forced expiratory volume in one second; FVC: forced vital capacity; $V^{\prime} \max , 50=$ maximal expiratory flow at $50 \%$ of FVC.
France) were applied around the head, using a 40-L Plexiglas canopy. The pressure input was measured with a Honeywell $176 \mathrm{PC} \pm 35 \mathrm{hPa}$ pressure transducer (Microswitch, Boston, MA, USA), and airway flow with a Fleisch No 2 pneumotachograph (Metabo, Epalinges, Switzerland) connected to a similar transducer with a matched frequency response. The signals were digitized at a rate of $128 \mathrm{~Hz}$, for periods of $16 \mathrm{~s}$, by a personal computer, and their fast Fourier transform (FFT) was computed using blocks of 256 points with $50 \%$ overlap. Impedance data from single measurements without obvious artefacts were taken. Total respiratory impedance is partitioned into a real part or resistance $(R)$ and an imaginary part or reactance $(X \mathrm{rs}): R$ was characterized by its mean value from $4-32 \mathrm{~Hz}(R \mathrm{~m})$ and by its value at $10 \mathrm{~Hz}(R 10)$, the lowest frequency at which satisfactory data were available in all subjects both before and after bronchoconstriction. Only impedance values with a coherence function $\gamma^{2}$ equal to or exceeding 0.95 were retained. This function is decreased in the presence of noise or alinearity in the relation of the pressure and flow signals.

Spirometry was performed using an electronic spirometer (Auto Spiro AS 500 Minato Medical Science Co. Ltd, Osaka, Japan). Forced vital capacity (FVC), FEV1 and maximal expiratory flows ( $\left.V^{\prime} \max \right)$ at various lung volumes were obtained by having the subject expire forcefully after a maximal inspiratory manoeuvre. At baseline at least three forced expiratory manoeuvres, satisfactory according to recommended criteria [13], were recorded; thereafter, only two reproducible curves were required. The largest FVC, FEV1 and $V^{\prime} \max$ at $50 \%$ of FVC $\left(V^{\prime} \max , 50\right)$ were retained for analysis. Results were expressed as a percentage of the predicted values of the European Coal and Steel Community Working Party [13].

\section{Bronchial responsiveness}

The carbachol bronchial challenge (CBC) test was performed according to a protocol used routinely in the pulmonary function laboratory of the Centre Hospitalier Universitaire of Nancy-Brabois [14]. Five cumulative doses of $320 \mu \mathrm{g}$ carbachol were administered in succession using an FDC 88 dosimeter (Mediprom 75014, Paris, France) delivering fixed doses of $80 \mu \mathrm{g}$ carbachol. breath $^{-1}$ $(4 \times 80 \mu \mathrm{g}=320 \mu \mathrm{g})$. A nose clip was worn and the aerosol inhaled through the mouth by slow inspiratory capacity manoeuvres followed by a 5-s breath hold. One minute after the inhalation of each cumulative dose of carbachol, impedance measurements and spirometry were performed in that order. The sequence (carbachol inhalation, impedance measurements and spirometry) was repeated until the fifth dose of carbachol (cumulative dose 1,600 $\mu \mathrm{g}$ ) was inhaled or when FEV1 fell by $\geq 20 \%$ from the baseline value. Patients who experienced a fall in FEV1 of $\geq 20 \%$ were classified as reactors. For these patients, the challenge was terminated by the inhalation of two puffs of salbutamol $(200 \mu \mathrm{g})$.

\section{Analysis of dose-response curves}

DRS were obtained for FEV1 and for two indices of FOT impedance namely $(R \mathrm{~m})$ and $(R 10)$. Both impedance 
Table 2. - Rank correlations between observed values of the forced oscillation technique and spirometric parameters under baseline conditions in patients undergoing carbachol bronchial challenge test $(\mathrm{n}=71)$

\begin{tabular}{lcc}
\hline Index & $R \mathrm{~m}$ & $R 10$ \\
\hline FEV1 & $-0.555^{* * *}$ & $-0.570 * * *$ \\
FVC & $-0.457 * * *$ & $-0.484 * * *$ \\
FEV 1/FVC & $-0.422^{* * *}$ & $-0.393^{* * *}$ \\
$V^{\prime} \max , 50$ & $-0.554 * *$ & $-0.545^{* * *}$ \\
\hline
\end{tabular}

FEV1: forced expiratory volume in one second; FVC: forced vital capacity; $V^{\prime} \max , 50$ : maximal expiratory flow at $50 \%$ of FVC; Rm: mean resistance from 4-32 Hz; R10: forced oscillation resistance at $10 \mathrm{~Hz} .{ }^{* * *}$ : $\mathrm{p}<0.001$.

parameters correlated significantly with all spirometric indices (table 2).

The dose of carbachol producing a $20 \%$ fall in FEV 1 (PD20) was calculated when possible by plotting the percentage fall in FEV1 against the dose of carbachol on a log scale and by interpolating the last two points [6]. PD values for $R \mathrm{~m}$ and $R 10$ were calculated in a similar manner as the PD of carbachol producing a $47 \%$ rise in $R \mathrm{~m}$ $(\mathrm{PD} 47, R \mathrm{~m})$ or in $R 10(\mathrm{PD} 47, R 10)$. This percentage change is equivalent to a $20 \%$ fall in FEV1: both correspond to 6.7 times the coefficient of variation of the parameter under baseline conditions [15].

Linear two-point DRS for FEV1 (DRSFEV1), Rm (DRS$R \mathrm{~m})$ and $R 10$ (DRSR10) were calculated by the method proposed by $\mathrm{O}^{\prime}$ CONNOR et al. [11] as the percentage fall of FEV1 or increase in $R \mathrm{~m}$ or $R 10$ at the last dose divided by the total dose of carbachol administered.

\section{Statistical analysis}

Statistical analysis was performed using the SAS package (SAS Institute, Cary, NC, USA) [16]. Correlation between FEV1- and Rm-derived parameters was assessed by the Spearman's rank correlation coefficient. The differences in $R \mathrm{~m}$ between reactors and nonreactors was assessed by the Mann-Whitney test. The accuracy of DRSRm, $\Delta \% R \mathrm{~m}$ (Initial $R \mathrm{~m}$-Final $R \mathrm{~m} /$ Initial $R \mathrm{~m} \times 100), \mathrm{DRS}_{R 10}$ and $\Delta \% R 10$ (Initial $R 10$-Final $R 10 /$ Initial $R 10 \times 100$ ), to detect BHR (defined in terms of a decline in FEV1 by $\geq 20 \%$ ) was assessed using ROC curves. The sensitivity corresponds to the ratio of true positive results to all positive results (i.e. true positive plus false negative), whereas the specificity corresponds to the ratio of true negative results to all negative results (i.e. true negative plus false positive). The false positive ratio corresponds to 1 -specificity. With the ROC curve, by plotting the false positive fraction against the sensitivity and varying the threshold of the FOT parameter, it is possible to define the threshold that offers the best compromise between the highest sensitivity and the highest false positive fraction. Ideally, this is the value giving a sensitivity equal to 1 and a specificity equal to 1 (i.e. 1 -specificity $=0$ ).

\section{Results}

A total of 294 paired measurements of spirometric and FOT parameters were obtained in the 71 patients. As expected, FEV1 decreased and $R \mathrm{~m}$ and $R 10$ increased with
Table 3. - Mean $\pm S D$ values of forced expiratory volume in one second ( $\mathrm{FEV} 1)$, mean resistance $4-32 \mathrm{~Hz}(R \mathrm{~m})$ and forced oscillation resistance at $10 \mathrm{~Hz}(R 10)$ before and at the end of the challenge test in 71 patients

\begin{tabular}{lccc}
\hline Index & Baseline & End-Test & $\mathrm{p}$-value \\
\hline $\mathrm{FEV} 1 \mathrm{~L}$ & $3.10 \pm 0.70$ & $2.73 \pm 0.77$ & 0.0001 \\
$R \mathrm{~m} \mathrm{hPa} \cdot \mathrm{s} \cdot \mathrm{L}^{-1}$ & $3.17 \pm 1.48$ & $6.01 \pm 5.18$ & 0.0001 \\
$R 10 \mathrm{hPa} \cdot \mathrm{s} \cdot \mathrm{L}^{-1}$ & $3.21 \pm 1.43$ & $5.56 \pm 3.21$ & 0.0001 \\
\hline
\end{tabular}

the development of bronchial narrowing (table 3). Of the 71 patients tested $23(32 \%)$ exhibited a fall in FEV1 of $\geq 20 \%$ and were considered as "spirometric" reactors. For comparison, 58 patients (82\%) had an increase in $R \mathrm{~m}$ $\geq 47 \%$ throughout the challenge, whereas for $R 10$ this was the case for 52 patients $(73 \%)$.

As expected, a highly significant correlation was found between $R \mathrm{~m}$ and $R 10$ both at baseline ( $\mathrm{r}=0.986$; $\mathrm{p}=0.0001)$ and at end-test $(\mathrm{r}=0.846 ; \mathrm{p}=0.0001)$. When PD values were compared with the corresponding DRS values, a strong correlation between PD20 and DRSFEV1 $(r=-0.962$; $\mathrm{p}=0.0001$ ) and a significant although weaker correlation between PD47, $R_{\mathrm{m}}$ and $\operatorname{DRS}_{\mathrm{m}}(\mathrm{r}=-0.648 ; \mathrm{p}=0.0001)$ and between PD47,R10 and DRSR10 ( $\mathrm{r}=-0.552 ; \mathrm{p}=0.0001)$ was observed. Comparisons between slopes showed a significant correlation between DRSFEV1 and either DRSRm, $(\mathrm{r}=$ $0.700 ; \mathrm{p}=0.0001)$ or $\mathrm{DRSR}_{10}(\mathrm{r}=0.784 ; \mathrm{p}=0.0001)$. Among spirometric reactors both the mean PD47,Rm and PD47,R10 were significantly lower and the corresponding DRS steeper (increased responsiveness) than among nonreactors (table 4).

ROC curves were constructed for $\mathrm{DRS} R \mathrm{~m}, \mathrm{DRS} R 10$, $\Delta \% R \mathrm{~m}$ and $\Delta \% R 10$ by plotting the sensitivity versus the false positivity of each index across the whole range of potential thresholds. Figure $1 \mathrm{a}$ and $\mathrm{b}$ ) shows that the curve for DRSRm lies much closer to the optimal upperleft corner than does the ROC curve for $\Delta \% R \mathrm{~m}$. For the $\mathrm{DRS} R \mathrm{~m}$ curve, the response that best separates reactors from nonreactors (defined in terms of the value that gives the greatest value for the sum of specificity and sensitivity) corresponded to a slope value of $0.060 \%$ rise in $R \mathrm{~m} \cdot \mu \mathrm{g}$ carbachol $^{-1}(91.3 \%$ sensitivity, $81.2 \%$ specificity, sum $=172.5 \%$ ). In practice, a slope of 0.060 corresponds to a rise in $R \mathrm{~m}$ of $96 \%$ after the inhalation of $1,600 \mu \mathrm{g}$ of carbachol. For the $\Delta \% R \mathrm{~m}$ curve the value that best separates reactors from nonreactors was $56 \%$ (86.9\% sensitivity; $52.1 \%$ specificity; sum $=139.0 \%$ ). These best value points are represented on the ROC curves by an arrow.

ROC curves for the indices of resistance at $10 \mathrm{~Hz}$ are shown in figure 2 ( $a$ and $b$ ). As for DRSRm the curve for $D_{R S} R_{10}$ lies much closer to the optimal upper-left corner than does the curve for $\Delta \% R 10$. For DRS $R 10$ the response that best separated reactors from nonreactors corresponds to a slope value of $0.066 \%$ rise in $R 10 \cdot \mu \mathrm{g}$ carbachol $^{-1}$ (91.3\% sensitivity; $95.8 \%$ specificity; sum $=187.1 \%)$. In practice, a slope of 0.066 corresponds to a rise in $R 10$ of $106 \%$ after the inhalation of $1,600 \mu \mathrm{g}$ of carbachol. For the $\Delta \% R 10$ curve the value that best separates reactors from nonreactors was 51\% (91.3\% sensitivity; $58.3 \%$ specificity; sum $=149.6 \%$ ). These best value points are represented on the ROC curves by an arrow.

To summarize the findings of ROC curves, the sensitivity of $\mathrm{DRS} R \mathrm{~m}, \mathrm{DRS} R 10$ and $\Delta \% R 10$ to separate reactors 
Table 4. - Mean \pm SD forced oscillation technique (FOT) indices in reactors* and nonreactors

\begin{tabular}{|c|c|c|c|c|}
\hline FOT index & All & Reactors & Nonreactors & p-value \\
\hline PD $47, R \mathrm{~m} \mu \mathrm{g}$ carbachol & $500 \pm 400$ & $247 \pm 195$ & $644 \pm 416$ & 0.0001 \\
\hline $\mathrm{DRS} R \mathrm{~m} \%$ rise $R \mathrm{~m} \cdot \mu \mathrm{g}$ carbachol $^{-1}$ & $0.104 \pm 0.158^{+}$ & $0.236 \pm 0.224 * *$ & $0.041 \pm 0.034^{\dagger}$ & 0.0001 \\
\hline PD47,R10 $\mu \mathrm{g}$ carbachol & $492 \pm 352$ & $340 \pm 341$ & $603 \pm 323$ & 0.001 \\
\hline $\mathrm{DRS}_{R 10} \%$ rise $R 10 \cdot \mu \mathrm{g}$ carbachol $^{-1}$ & $0.091 \pm 0.141^{\#}$ & $0.214 \pm 0.198^{*}$ & $0.032 \pm 0.023^{\S}$ & 0.0001 \\
\hline
\end{tabular}

$\mathrm{PD} 47, R \mathrm{~m}$ : provocative dose leading to a rise in mean resistance $\geq 47 \%$; PD47,R10: provocative dose leading to a rise in resistance at $10 \mathrm{~Hz}$ $\geq 47 \%$; DRS $R$ m: dose-response slope of mean resistance; DRSR10: dose-response slope of resistance at $10 \mathrm{~Hz} . *$ : defined in terms of a fall in forced expiratory volume in one second of $20 \%{ }^{+}$: slope corresponding to a $166 \%$ increase in mean resistance $(4-32 \mathrm{~Hz})(R \mathrm{~m}) ; * *$ : slope corresponding to a $378 \%$ increase in $R \mathrm{~m}$; ${ }^{\star}$ : slope corresponding to a $66 \%$ increase in $R \mathrm{~m}$; ${ }^{\#}$ : slope corresponding to a $146 \%$ increase in forced oscillation resistance at $10 \mathrm{~Hz}(R 10) ;{ }^{\S}$ : slope corresponding to a $342 \%$ increase in $R 10{ }^{\S}$ : slope corresponding to a $51 \%$ increase in $R 10$; after the inhalation of $1,600 \mu \mathrm{g}$ of carbachol.

from nonreactors was identical to one another, but the specificity of DRSR10 was superior to that of the other indices.

\section{Discussion}

Various indices were proposed for summarizing the dose-response data in bronchial challenge testing, the
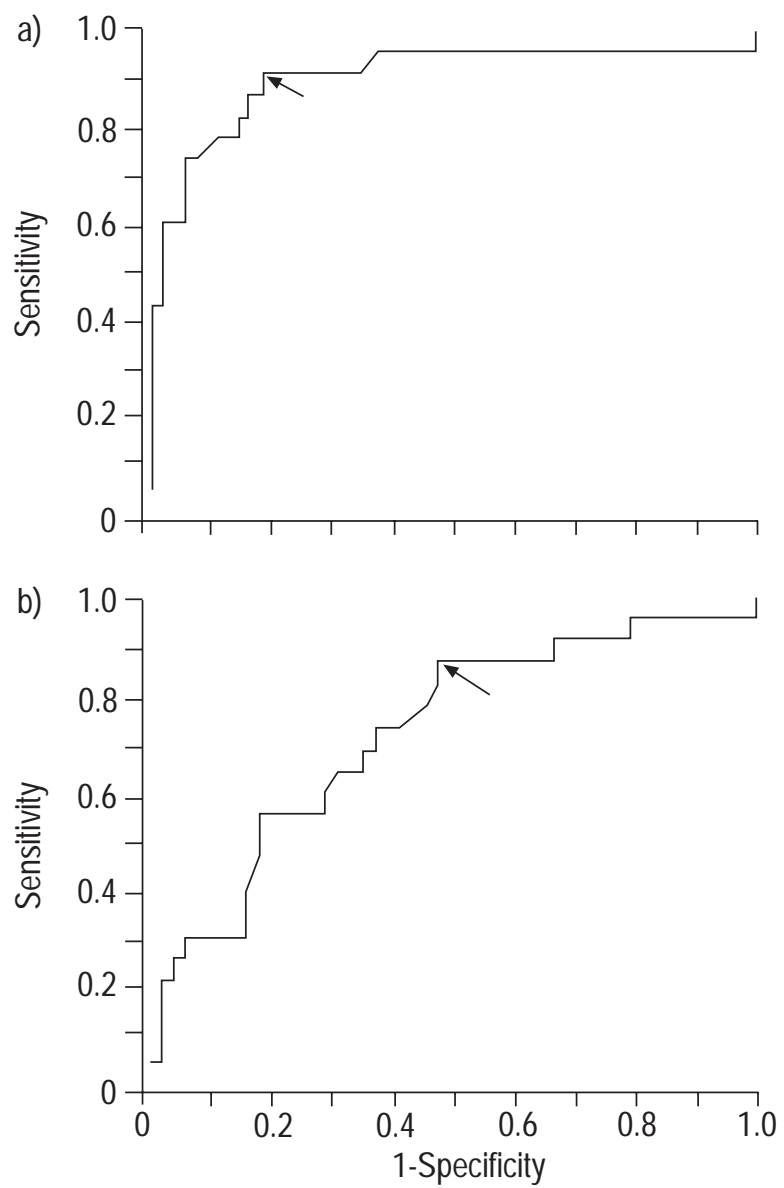

Fig. 1. - a) Receiver operating characteristics (ROC) curve obtained with dose-response slope of mean resistance (DRS $R \mathrm{~m}$ ). The arrow indicates the point on the curve that is closest to the ideal point i.e. is the threshold value of DRSRm $(0.060 \%$ rise in mean resistance $(4-32 \mathrm{~Hz})$ $(R \mathrm{~m}) \cdot \mu \mathrm{g}$ carbachol $\left.^{-1}\right)$ that provides the best compromise between the sensitivity and 1-specificity (sensitivity $91.3 \%$, specificity $81.2 \%$ ). b) ROC curve obtained with $\Delta \% R \mathrm{~m}$. The arrow indicates the point on the curve that is closest to the ideal point i.e. the threshold value of $\Delta \% R \mathrm{~m}$ $(56 \%)$ that provides the best compromise between the sensitivity and 1specificity (sensitivity $86.9 \%$, specificity $52.1 \%$ ). most common of which is the PD of bronchoconstrictor leading to a specified decrement in lung function. In this study, a PD20 value could be calculated for 23 patients, a PD $47, R \mathrm{~m}$ for 58 patients and a PD47,R10 for 52 patients, thus giving a prevalence rate of BHR of 32,82 and $73 \%$ according to the parameter used. Regardless of the possible explanations for this difference, it should be noticed that the proportion of subjects for whom a PD20 could be calculated seems rather low if it is considered that the study group was formed by patients with pulmonary and other diseases likely to be associated with BHR. Obviously this proportion is expected to be even lower in population or occupational samples without overt pulmonary diseases.

A nearly perfect correlation between PD20 and DRSFEV 1 was observed. This finding, which is in agreement with previous work by O'CONNOR et al. [11], supports the view that DRSFEV1 provides the same information as PD20 for hyperresponsive subjects while providing information for less reactive subjects as well. Although they were highly significant, the correlations between PD $47, R \mathrm{~m}$ and DRS $R \mathrm{~m}$ and between PD47,R10 and DRSR10 were weaker than that between PD20 and DRSFEV1, and should therefore be interpreted more cautiously.

The sensitivity and specificity of DRSRm and, especially, DRSR 10 to detect "spirometric" BHR $(\mathrm{BHR}=$ decline in FEV $1 \geq 20 \%$ ) can be considered satisfactory for two reasons. Firstly, it should be kept in mind that whereas Raw measured by FOT evaluates the patency of the airways during quiet breathing, FEV1 does so during a forced expiratory manoeuvre. This major physiological difference provides a reasonable explanation for the well-known [17] lack of perfect correlation between FOT resistance and FEV1 at baseline, a finding confirmed in this study (table 2 ). Secondly, by definition, the calculation of the sensitivity and specificity of DRSRm and DRSR10 requires knowledge of the true status of the patients with respect to bronchial responsiveness. In other words, this means that the reference test must be as close to reality as possible. In the present study, a threshold of fall in FEV1 of $20 \%$ was adopted as reference not because it is the indisputable "gold standard" for BHR, but simply because it is the most widely employed. In fact, the authors believe that using FEV1 as a reference test may have been detrimental for the FOT parameters. Indeed, since the latter are considered to be more accurate detectors of changes in airway calibre than FEV1 [18-26] the possibility that the specificity of FOT parameters (e.g. DRS $R \mathrm{~m}$ and $\Delta \% R \mathrm{~m})$ was negatively influenced by misclassification errors occurring with FEV1 cannot be ruled out entirely. 

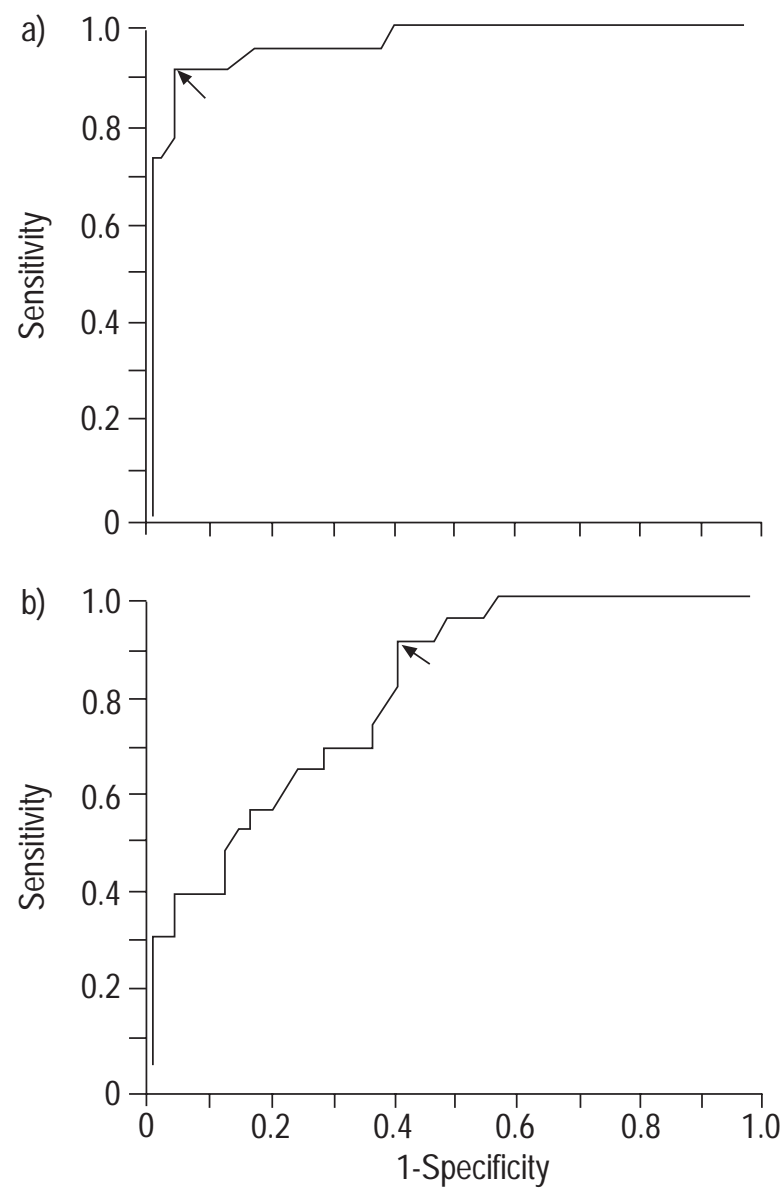

Fig. 2. - a) Receiver operating characteristics (ROC) curve obtained with dose-response slope of forced oscillation resistance at $10 \mathrm{~Hz}$ (DRSR10). The arrow indicates the point on the curve that is closest to the ideal point i.e. is the threshold value of DRSR10 (0.066 \%rise in forced oscillation resistance at $10 \mathrm{~Hz}(R 10) \cdot \mu \mathrm{g}$ carbachol $\left.^{-1}\right)$ that provides the best compromise between the sensitivity and 1-specificity (sensitivity $91.3 \%$, specificity $95.8 \%$ ). b) ROC curve obtained with $\Delta \% R 10$. The arrow indicates the point on the curve that is closest to the ideal point i.e. the threshold value of $\Delta \% R 10(51 \%)$ that provides the best compromise between the sensitivity and 1-specificity (sensitivity $91.3 \%$, specificity $58.3 \%)$.

The sensitivity of FOT indices in detecting changes in bronchial calibre in bronchial challenge testing has been compared with that of spirometry performed quasi-simultaneously. SOLYMAR et al. [18] found FOT indices to be more discriminative than forced expiration in detecting BHR to pollen in children with seasonal asthma DUIVERMAN et al. [19] showed that FOT indices compared well with indices from maximal and partial flow-volume curves in young asthmatics in a stable condition. SNASHALL et al. [20] performed histamine challenge tests in adult asthmatics and observed a close correlation between PD values for FEV1 and for FOT impedance and concluded that the latter was more sensitive because a smaller dose of histamine gave a diagnostic result. WESSELING and WoutERS [21] examined a small group of asthmatics after increasing rates of isocapnic hyperventilation of cold air and found FOT parameters to be more sensitive than spirometry in differentiating between normals and asthmatics. Later, the same team found a good correlation between FOT impedance and spirometry in a larger group of asth- matics ( $\mathrm{n}=60$ ) whose PD20 to histamine was $\leq 8 \mu \mathrm{mol}$ [22]. WeERSINK et al. [23] measured FOT impedance and spirometry in stable asthmatics during the inhalation of histamine and methacholine and found that the dose of histamine provoking a $40 \%$ increase in FOT resistance measured at $8 \mathrm{~Hz}$ was the parameter that gave the lowest burden to the patient: it was reached at a three-fold lower concentration than provocative concentration causing a $20 \%$ decrease in FEV1, thus shortening considerably the procedure and lowering the drug load. Recently, ScHMEKEL and SмIтH [24], using ROC curves, showed that FOT parameters are more sensitive and more specific than FEV1 at detecting bronchoconstriction occurring in asthmatic patients stimulated with isocapnic hyperventilation of cold air. Similar results were observed in the few studies comparing FOT, spirometry and plethysmography performed quasi-simultaneously. FeIHL et al. [25] observed that both FOT impedance and plethysmography were more sensitive than spirometry in detecting bronchoconstriction in adult asthmatics undergoing an allergen challenge test. Finally, VAN NoORD et al. [26] observed that the relative change in plethysmographic airway conductance, the reciprocal of FOT resistance at $6 \mathrm{~Hz}$, the reciprocal of FOT resistance from $2-26 \mathrm{~Hz}$, and FEV1 were, in this order, the most sensitive parameters for detecting BHR to histamine in subjects with a history of episodic wheezing. However, in none of the above series were FOT parameters or FEV1 expressed in terms of DRS, so they cannot be compared with the data of the present study.

A word must be said regarding the validity of the protocol of the present study. In order to avoid the influence of differences in baseline bronchial tone and/or fluctuations in bronchial responsiveness, FOT parameters and spirometry were measured during the same challenge. The measurements were carried out between 2 and 4 min after the inhalation of carbachol, a time interval likely to coincide with the plateau phase of the bronchial response to carbachol [27]. On the other hand, since deep inspiratory manoeuvres can alter bronchial tone [4], all measurements were carried out in a fixed sequence, with FOT parameters being systematically evaluated before spirometry. It should be stressed that the modified forced oscillations apparatus used in this study, the so-called "head generator" obviates one of the major disadvantages of the technique i.e. the increase of the upper airways artefact with increasing pulmonary resistance [12].

Interestingly, for the same level of sensitivity (91.3\%), a substantially better specificity was seen for DRSR10 $(95.8 \%)$ than for DRSRm $(81.2 \%)$. This finding is in agreement with previous observations suggesting that resistance at low frequency is a better index than highfrequency resistance or $R \mathrm{~m}$ to assess BHR [19, 27].

The advantages of the forced oscillation technique over spirometry in bronchial challenge testing have been pointed out previously [18-26] and have been confirmed in the present study. However, as far as population studies are concerned, such advantages (e.g. ease of measurement, no need for cooperation, etc.) are overshadowed by the mode of expression of the results because conventional indices of responsiveness allow the characterization of only a small proportion of subjects. This study showed that expressing the forced oscillation technique data in terms of the two-point linear dose-response slope of O'CONNOR et al. [11] adds to the advantages of the method by providing 
a quantitative index of bronchial responsiveness for all subjects. The index is simple and easy to calculate being potentially useful in occupational epidemiology, especially when large populations are to be examined at the work place during working hours. Further studies are necessary to demonstrate the validity of dose-response slopes of mean resistance and resistance at $10 \mathrm{~Hz}$ in this setting, when a small proportion of spirometric reactors is likely to be found.

Acknowledgements. The authors thank H. Uffholtz for allowing us to examine patients undergoing challenge testing in his laboratory, A Berthelin for her technical assistance and N. Lorentz for her invaluable assistance in the statistical analysis.

\section{References}

1. Cockroft DW, Killian DN, Mellon JJA, Hargreave FE. Bronchial reactivity to inhaled histamine: a method and clinical survey. Clin Allergy 1977; 7: 235-243.

2. Rijcken B, Schouten JP, Weiss ST, Speizer FE, Van der Lende $\mathrm{R}$. The relationship of nonspecific bronchial responsiveness to respiratory symptoms in a random population sample. Am Rev Respir Dis 1987; 136: 62-68.

3. Kennedy SM, Burrows B, Vedal S, Enarson DA, ChanYeung M. Methacholine responsiveness among working populations. Relationship to smoking and airway caliber. Am Rev Respir Dis 1990; 142: 1377-1383.

4. Nadel JA, Tierney DF. Effect of a previous deep inspiration in airway resistance in man. J App Physiol 1961; 16: 717-719.

5. Peslin R, Saunier C, Gallina C, Duvivier C. Small-amplitude pressure oscillations do not modify respiratory mechanics in rabbits. J Appl Physiol 1994; 76: 1011-1013.

6. Sterk PJ, Fabbri LM, Quanjer $\mathrm{PhH}$, et al. Airway responsiveness. Standardized challenge testing with pharmacological, physical and sensitizing stimuli in adults. Eur Respir J 1993; 6: Suppl. 16, 58-83.

7. Cockroft DW, Berscheid BA. Slope of the dose-response curve: usefulness in assessing bronchial responses to inhaled histamine. Thorax 1983; 38: 55-61.

8. Neukirch F, Maccario J, Korobaeff M, et al. Analysis of the methacholine dose-response curve: usefulness of a simplified log-logistic model in epidemiologic studies. Bull Eur Physiopathol Respir 1987; 23: 383-386.

9. Bruschi C, Cerveri I, Zola MC, Maccarini L, Grassi M, Rampulla C. Bronchial responsiveness to inhaled methacholine in epidemiological studies: comparison of different indices. Eur Respir J 1989; 12: 630-636.

10. Sherrill DL, Martinez FD, Sears MR, Lebowitz MD. An alternative method for comparing and describing methacholine response curves. Am Rev Respir Dis 1993; 148: 116-122.

11. O'Connor G, Sparrow D, Taylor D, Segal M, Weiss S. Analysis of dose-response curves to methacholine. An approach suitable for population studies. Am Rev Respir Dis 1987; 136: 1412-1417.

12. Peslin R, Marchal F, Duvivier Q, Ying Y, Gallina C. Evaluation of a modified head generator for respiratory impedance measurements. Eur Respir Rev 1991; 1: 140145.

13. Quanjer PhH, Tammeling GJ, Cotes JE, Pedersen OF, Peslin R, Yernault J-C. Lung volumes and forced respiratory flows. Report working party. Standardization of Lung Function Tests. European Community for Coal and Steel. Eur Respir J 1993; 6: Suppl. 16, 5-40.

14. Bohadana AB, Peslin R, Uffholtz H, Pauli G. Potential for lung sound monitoring during bronchial provocation testing. Thorax 1995; 50: 955-961.

15. Kostianev S, Bohadana AB, Peslin R, Duvivier C, Gallina C. Diurnal variations of respiratory impedance parameters. Eur Respir Rev 1994; 4: 167-171.

16. SAS/STAT User's Guide. Version 6. Cary NC. SAS Institute, 1989.

17. Peslin R, Pham QT, Teculescu D, Gallina C, Duvivier C. Comparative value of respiratory input and transfer impedances in field studies. Bull Eur Physiopathol Respir 1987; 23: 37-42.

18. Solymar L, Aronsson P-H, Engström I, Bake B, Bjure J. Forced oscillation technique and maximum expiratory flows in bronchial provocation tests in children. Eur $J$ Respir Dis 1984; 65: 486-495.

19. Duiverman EJ, Neijens HJ, Van der Snee-van Smaalen M, Kerrebijn KF. Comparison of forced oscillometry and forced expirations for measuring dose-related responses to inhaled methacholine in asthmatic children. Bull Eur Physiopathol Respir 1986; 22: 433-436.

20. Snashall PD, Parker S, Phil M, Ten Haave P, Simmons D, Noble MIM. Use of an impedance meter for measuring airway responsiveness to histamine. Chest 1991; 99: 1183-1185.

21. Wesseling GJ, Wouters EFM. Respiratory impedance measurements in a dose response study of isocapnic hyperventilation with cold air. Respiration 1992; 59: 259264.

22. Wesseling GJ, Vanderhoven-Augustin IML, Wouters EFM. Forced oscillation technique and spirometry in cold air provocation tests. Thorax 1993; 48: 254-259.

23. Weersink EJM, VD Elshout FJJ, Herwaarden CV, Folgering $\mathrm{H}$. Bronchial responsiveness to histamine and methacholine measured with forced expirations and with the forced oscillation technique. Respir Med 1995; 89: 351-356.

24. Schmekel B, Smith H-J. The diagnostic capacity of forced oscillations and forced expiration techniques in identifying asthma by isocapinic hyperpnoea of cold air. Eur Respir J 1997; 10: 2243-2249.

25. Feihl F, Badan M, Depeursinge F, et al. Respiratory acoustical impedance: a new technique to measure airway response during bronchial inhalation challenges. Ann Allergy 1988; 61: 263-268.

26. Van Noord JA, Clement J, Van de Woestijne KP, Demedts $M$. Total respiratory resistance and reactance as a measurement of response to bronchial challenge with histamine. Am Rev Respir Dis 1989; 139: 921-926.

27. Orehek J, Gayrard P, Smith AP, Grimaud C, Charpin J. Airway response to carbachol in normal and asthmatic subjects. Am Rev Respir Dis 1977; 115: 937-943.

28. Bisgaard H, Klug B. Lung function measurement in awake young children. Eur Respir J 1995; 8: 2067-2075. 